\title{
Who should be prioritised for COVID-19 vaccination?
}

\author{
Fiona M Russell $\left(\mathbb{D}^{\mathrm{a}}{ }^{\mathrm{a} b}\right.$ and Brian Greenwood ${ }^{\mathrm{c}}$ \\ ${ }^{a}$ Department of Paediatrics, The University of Melbourne, Melbourne, Australia; ${ }^{b}$ Asia-Pacific Health Research, Murdoch Children's Research Institute, \\ Melbourne, Australia; 'Department of Disease Control, London School of Hygiene and Tropical Medicine, London, UK
}

\begin{abstract}
The development of COVID-19 vaccines is occurring at a rapid pace, with the potential for a vaccine to be available within 6 months. So who should be prioritized for vaccination when in the first instance, there will be insufficient supply to meet demand? There is no doubt that health-care workers in all settings should be vaccinated first, but who comes next will be a complex decision based on local epidemiology, societal values, and the ability of the vaccines to prevent both severe disease and to reduce transmission thereby eliciting herd protection. The decision on who to vaccinate should be equitable, highly contextualized, and based on the property of each vaccine. In some settings, the elderly may be prioritized, in others, it may be the population most likely to get infected and responsible for community spread. To support decision-making on who to be prioritized for vaccination requires urgent additional research on the epidemiology of COVID-19; preexisting immunity and who is responsible for transmission in a variety of settings; the safety, immunogenicity, and efficacy of COVID-19 vaccines in children and pregnant women; and determining whether COVID-19 vaccines prevent asymptomatic infection and transmission.
\end{abstract}

\section{ARTICLE HISTORY}

Received 27 August 2020

Accepted 21 September 2020

\section{Keywords}

COVID-19 vaccines; high-risk; epidemiology; transmission; vaccine development; clinical trials
COVID-19 vaccines are being developed at a furious pace. There are already six vaccines in phase 3 clinical trials from Moderna/NIAID, University of Oxford/AstraZeneca, BioNTech/Fosun Pharma/Pfizer, and three from Chinese companies, Sinovac, Wuhan Institute of Biological Products/ Sinopharm, and Beijing Institute of Biological Products/ Sinopharm. ${ }^{1}$ Hundreds of millions of doses of vaccine may be ready for roll-out by the end of 2020 or early 2021 .

At least 14 high-income countries are prospectively buying vaccines before they have even been cleared for use. ${ }^{1}$ The US deals with Pfizer-BioNTech, AstraZeneca/Oxford, SanofiGlaxo, Moderna, Novovax, and Johnson \& Johnson are using American buying power to avoid paying excessive prices. The UK has done deals with providers for more than 250 million doses of COVID-19 vaccines. Recently, Australia announced an agreement with AstraZeneca to buy 25 million doses provided the Oxford vaccine is safe and effective. The Coalition for Epidemic Preparedness Innovations (CEPI), which coordinates the global COVID-19 vaccine development effort, together with the World Health Organization, and Gavi, The Vaccine Alliance, has developed the COVAX Facility to ensure equitable global access to COVID-19 vaccines once these are available.

Who should be prioritized once vaccines become available? In the first instance, not enough vaccines will be available for the entire global population of almost eight billion to be vaccinated, so difficult decisions will need to be made as to who gets vaccinated first, as prioritization is inevitable and some people will have to wait. There is general agreement that health-care workers in all settings, should be vaccinated first, not only for their own benefit, but also to ensure the effective running of the health system. In the UK and the USA, the risk of reporting a positive test for COVID-19 was 11-fold higher among frontline health-care workers compared to the general public. ${ }^{2}$

After health-care workers, who should be next? Herein lies profound societal and ethical dilemmas- should the elderly, who are most at risk of severe disease and death, be the target, or should the age groups that transmit the virus most frequently and who are most engaged in the economic functioning of society be vaccinated next? There are already indications that the pandemic and mitigation measures are having broad indirect health effects. In the UK, there are delays in cancer screening, diagnosis, and subsequent treatment services due to changes in service delivery or fear of going out, which may result in thousands of excess deaths. ${ }^{3}$ Where SARS-CoV-2 population-based testing rates are high, people aged 20-49 years have consistently been shown to have high SARSCoV-2 infection rates. ${ }^{4,5}$ Hence, strategically vaccinating those most likely to get infected and to transmit the infection could also protect most of the community through herd protection, allowing the workforce to function and preventing the indirect adverse societal and health effects of the epidemic. Herd protection has been demonstrated in varying degrees for a number of vaccines including the pneumococcal conjugate vaccine, with vaccination of young children (the age group most responsible for transmitting pneumococci) protecting the elderly from pneumococcal disease through indirect effects. ${ }^{6}$

Deciding how much priority to give to direct protection, i.e. preventing severe disease in high-risk groups, or to the indirect effects, i.e. preventing overall transmission in the community (and the high-risk groups), and allowing everyday activities to resume with consequent economic benefits to the whole community, will be a challenge for public health authorities. Workers in high-risk employment could be given priority. 
The Swedish Public Health Authority compared SARS-CoV-2 infection risk by profession in their country, and found that front-line workers such as taxi drivers, pizza chefs, and public transport drivers had more than a four-fold higher risk of infection than other workers. In contrast, Swedish teachers and childcare workers had no increased risk compared to other professions. ${ }^{7}$

Decisions on which vaccine to use will depend on the vaccine's properties in terms of efficacy against severe disease and transmission, and whether the desired public health outcome is to prevent severe disease and/or to prevent transmission. Ideally, a COVID-19 vaccine will do both. There are early indications that some vaccines are immunogenic in clinical trials, ${ }^{8-10}$ and prevent disease in non-human primate models. Yet some vaccines may be less effective in preventing transmission, as demonstrated by the lack of difference in nasal shedding of the virus between vaccinated and unvaccinated groups. $^{11}$ It is imperative that clinical trials include SARSCoV-2 viral shedding outcomes, and that further progress is made on how to measure indirect protection and demonstrate the ability of a vaccine to prevent asymptomatic infection and transmission.

If prioritizing people to be vaccinated is decided according to risk, then age is a key factor as in many studies from highincome studies, the elderly had a much higher risk of death from COVID-19 than the young, with a dramatic and progressive increase in risk in those over 65 years of age. ${ }^{12}$ In the case of some other vaccines, such as influenza, the elderly require more antigen to develop a protective immune response, and more antigen in each dose may result in more side effects. ${ }^{13}$ Some COVID-19 vaccine developers are, therefore, looking at different dosage regimens for this age group and also at the use of powerful adjuvants. When the vaccine is in short supply, whether to include the very old as a priority group becomes an ethical issue, one that each country will need to consider based on what's acceptable to their population. Traditionally, vaccines need to show disability adjusted life years saved (DALYs)- this is the sum of the years of potential life lost due to premature mortality and the years of productive life lost due to disability. For the very old, the number of DALYs saved by vaccination will be quite low, as one DALY represents the loss of the equivalent of 1 year of full health. As the average life expectancy at birth varies considerably across the world, the proportion of the population who will require vaccination if this focuses on the elderly will vary by country. ${ }^{14}$ In lowincome countries, only a small proportion of the population would be considered elderly, so other factors will be important in terms of setting priorities on who to vaccinate.

Other key risk factors that predict the risk of death from COVID-19 include the presence of co-morbidities. A study from the UK found diabetes, severe asthma and various other medical conditions, including hypertension, to be risk factors for a COVID-19 related death. ${ }^{12}$ A modeling study estimated that 1.7 billion people, comprising $22 \%$ of the global population, have at least one underlying condition that puts them at increased risk of severe COVID-19 infection (ranging from $<5 \%$ of those younger than 20 years to $>66 \%$ of those aged 70 years or older). ${ }^{15}$ The proportion of the population at increased risk was highest in countries with older populations,
African countries with a high HIV/AIDS prevalence, and small island nations (such as Pacific island and Caribbean countries) with a high prevalence of diabetes. Estimates of the number of individuals at increased risk were most sensitive to the prevalence of chronic kidney disease, diabetes, cardiovascular disease, and chronic respiratory disease. ${ }^{15}$ In South Africa, a study found that HIV doubled the mortality risk from COVID-19, and previous tuberculosis had a similar impact. ${ }^{16}$

Variations in the epidemiology of the infection in different geographical locations, which are still not fully understood, will make it necessary to weight the balance between different risk factors in each geographical region. There are very few data from low- and middle-income countries (LMIC) regarding who is most at risk of a severe COVID-19 outcome. The epidemiology of the infection may differ considerably in LMIC from that in high-income countries as the demography, household transmission dynamics, comorbidities by age group and access to life saving treatment, such as oxygen and intensive care will be different. There is some suggestion that the mortality in Africa and India may be lower than in highincome countries and it is postulated that this could be due to differences in exposure to other infectious diseases which may alter trained immunity. ${ }^{17}$ Ethnicity may also be a key risk factor. In the UK, Black and South Asian people were at higher risk compared with people of White background, even after adjustment for other factors. ${ }^{12}$ A cross-sectional study from Brazil found that compared with White Brazilians, Pardo, and Black Brazilians with COVID-19 who were admitted to hospital had a significantly higher risk of mortality. Pardo ethnicity was the second most important risk factor (after age) for death. ${ }^{18}$ In some settings, indigenous populations are at high risk, and therefore have a case for priority.

Understanding risk factors for children and women is also critical because widespread poverty and malnutrition in LMICs may put these groups at enhanced risk. However, as yet, there are no studies to support this. There are very few studies of COVID-19 in pregnant women, especially from LMICs. The COVID-19 pandemic is likely to have substantial direct and indirect effects on perinatal outcomes in LMIC due to the direct effect of the virus and through disruption of routine essential maternity and newborn services. ${ }^{19}$ There are challenges to determining the true burden of COVID-19 in pregnancy as women are more likely to protect themselves from contracting COVID-19 by staying at home, for fear of infecting their unborn child, and are therefore not being tested and counted. Most of what is currently known of SARS-CoV-2 during pregnancy is drawn from high-income countries. There is evidence of perinatal SARS-CoV-2 transmission but the clinical outcomes of the newborns have, so far, been favorable. ${ }^{20}$ Although data from the UK found that the risk of being infected with SARS-CoV-2 is no higher in pregnant women compared with non-pregnant women of child-bearing age, ${ }^{21}$ recent data from the US suggest the odds of requiring mechanical ventilation is $50-70 \%$ higher in pregnant women compared with non-pregnant women of child-bearing age. ${ }^{22}$ A UK study found that obesity, diabetes, and being Black are all risk factors for hospital admission with SARS-CoV-2 during pregnancy. ${ }^{21}$ Deaths in non-pregnant people with type 1 and type 2 diabetes rose sharply during the initial COVID-19 
pandemic in England. Increased COVID-19-related mortality was associated not only with cardiovascular and renal complications of diabetes but also, independently, with glycemic control and body mass index. ${ }^{23}$ In Brazil, most COVID-19related deaths among pregnant women were reported between the age of 30-39 years, and diabetes, heart disease, obesity, hypertension, and asthma were linked to death. ${ }^{24}$ Small island countries in the Caribbean and the Pacific, with high rates of preexisting or gestational diabetes which is not well controlled, and limited access to oxygen and ICU support, may be a key target for vaccination. ${ }^{25}$ Yet it seems that very few COVID-19 vaccine developers have pregnant women in their vaccine pipeline plan. ${ }^{26}$ Safety needs to be established first in otherwise healthy adults as enhanced disease is a potential risk of this vaccine. ${ }^{27}$ But what amount of safety data would be required to allow pregnant women to be included in clinical trials? Currently, there is only one vaccine developer including pregnant women in clinical trials.

In view of the data presented above, the priority groups for vaccination in high-income countries whose priority is to prevent deaths and severe disease are likely to be healthcare workers, the elderly and those with a variety of comorbidities, although both of the latter groups may need vaccines of enhanced potency. If transmission is to be stopped, targeting workers who are at high risk of infection and transmission and who cannot work from home and who are in contact with high-risk groups will be key. This would include workers in homes for the elderly, public transport workers, and those in the service industry- this will vary by setting. However, where do children, adolescents, and young people feature in terms of prioritization for vaccination? Children have consistently been shown to have a lower burden of COVID-19 disease than adults and hence, at first, do not appear to be high on the priority list for vaccination. Young children are important drivers of other common respiratory viruses, ${ }^{28}$ but the role that they play in the transmission of SARS-CoV-2 virus in either high- or LMICs is still not fully determined. Studies have found that contact patterns vary by ethnicity and, as in the case of pneumococcal conjugate vaccines, the age group acting as an ongoing reservoir for infection shifts once a vaccine is introduced. ${ }^{29}$ School closures, which are so important during community transmission, mean that understanding transmission in this population is challenging as studies are confounded by public health mitigation measures. Additionally, there are few studies that include serology and asymptomatic contacts which limits the understanding of true infection rates and transmission potential in this group. A comparison between Finland (which closed schools) versus Sweden (which did not, except for children $>16$ years who schooled remotely) reassuringly found that the rates of infection in day care centers and school children were no different between countries, and primary school closure and reopening in Finland did not have any significant impact on the weekly number of laboratory-confirmed cases in primary school-aged children. ${ }^{30}$

Nevertheless, outbreaks in schools and school camps have occurred so it is important to understand the conditions that enable this to happen. A study from Israel found that an extreme heatwave, necessitating the relaxation of mask wearing and the need for air-conditioning, large numbers of children in a classrooms, and social contact through extracurricular activities and travel by school bus, were all factors that contributed to a large outbreak in a secondary school. ${ }^{31}$ In the US, an outbreak in attendees at a school summer camp found attack rates in children aged 6-10 years, 11-17 years, and $18-21$ years to be extra-ordinarily high $-51 \%, 44 \%$, and $33 \%$, respectively. ${ }^{32}$ These findings demonstrate that children are susceptible to SARS-CoV-2 infection and that they appear to efficiently spread SARS-CoV-2virus in some circumstances. In addition, a recent study found that children younger than 5 years old with mild to moderate COVID-19 may have high amounts of SARS-CoV-2 viral RNA in their nasopharynx. ${ }^{33}$ Although this study did not detect infectious virus, other studies have found a correlation between high nucleic acid levels and the ability to culture infectious virus, ${ }^{34}$ suggesting that young children can potentially be important drivers of SARS-CoV-2 spread in the general population. In many countries, especially in LMIC, classroom sizes are large, classrooms may be small in physical size, hand washing facilities are minimal or non-existent, and the heat may make the wearing of face masks unachievable, making public health control measures unrealistic. ${ }^{35}$ The school setting may be a very important reservoir and source for ongoing transmission and outbreaks. If this is the case, then vaccinating school-age children may be necessary to interrupt transmission. However, there are only three vaccine developers who are currently including children in clinical trials.

Ideally, the most effective way to return life to normal is a COVID-19 vaccine that prevents disease, prevents asymptomatic infection, and stops transmission. However, when vaccine supply cannot meet demand, the decision on who to vaccinate needs to be an equitable one, highly contextualized, based on the properties of the vaccine and whether the reduction of severe disease, interruption of transmission or both are desired. Most importantly, governments need to make decisions based on their own local epidemiology, priorities, and societal values. Therefore, there is an urgent need for further research on the epidemiology of COVID-19 and determining who is responsible for transmission in a variety of settings; the safety, immunogenicity, and efficacy of COVID-19 vaccines in children and pregnant women; and determining whether COVID-19 vaccines prevent asymptomatic infection and transmission.

\section{Disclosure of potential conflicts of interest}

Fiona Russell receives grant funding from the Australian National Health and Medical Research Council, The Wellcome Trust, the World Health Organization, the Bill \& Melinda Gates Foundation and the Australian Department of Foreign Affairs and Trade. In the past, she has received funds from Gavi, the Vaccine Alliance.

Brian Greenwood receives grant funding from the UK Joint Global Health Trials (The Department of Health and Social Care, the Department for International Development, the Global Challenges Research Fund, the 
Medical Research Council and the Wellcome Trust) programme and from PATH. In recent years he has also received funding from the Bill \& Melinda Gates Foundation and from The Welcome Trust.

\section{Acknowledgments}

We wish to thank Rita Reyburn for assistance with formatting the manuscript.

\section{Funding}

Fiona Russell's personal support comes from an Australian National Health and Medical Research Council Investigator grant and The University of Melbourne. Brian Greenwood's personal support comes from the London School of Hygiene \& Tropical Medicine;Australian National Health and Medical Research Council;

\section{ORCID}

Fiona M Russell (iD) http://orcid.org/0000-0002-3077-9639

\section{References}

1. The COVID-19 vaccine manufacturing and supply deals BioPharmaDispatch. [accessed 2020 Aug 27]. https://pharmadis patch.com/news/the-covid-19-vaccine-manufacturing-and-supply -deals

2. Nguyen LH, Drew DA, Graham MS, Joshi AD, Guo C-G, Ma W, Mehta RS, Warner ET, Sikavi DR, Lo C-H, et al. Risk of COVID-19 among front-line health-care workers and the general community: a prospective cohort study. Lancet Public Heal. 2020;5(9):e475e483. doi:10.1016/s2468-2667(20)30164-x.

3. Maringe C, Spicer J, Morris M, et al. The impact of the COVID-19 pandemic on cancer deaths due to delays in diagnosis in England, UK: a national, population-based, modelling study. Lancet Oncol. 2020;21:1023-34.

4. Perez-Saez J, Lauer SA, Kaiser L, et al. Serology-informed estimates of SARS-CoV-2 infection fatality risk in Geneva, Switzerland. Lancet Infect Dis 2020 Jul 14;S1473-3099(20)30584-3. doi:10.1016/S1473-3099(20)30584-3.

5. Coronavirus (COVID-19) at a glance infographic collection | Australian Government Department of Health. [accessed 2020 Aug 27]. https://www.health.gov.au/resources/collections/corona virus-covid-19-at-a-glance-infographic-collection

6. Ahmed SS, Pondo T, Xing W, McGee L, Farley M, Schaffner W, Thomas A, Reingold A, Harrison LH, Lynfield R, et al. Early Impact of 13-valent pneumococcal conjugate vaccine use on invasive pneumococcal disease among adults with and without underlying medical conditions-United States. Clin Infect Dis. 2020;70 (12):2484-92. doi:10.1093/cid/ciz739.

7. Folkhälsomyndigheten. Förekomst av covid-19 i olika yrkesgrupper. [accessed 2020 Aug 26. www.folkhalsomyndigheten.se/publi cerat-material/.

8. Jackson LA, Anderson EJ, Rouphael NG, Roberts PC, Makhene M, Coler RN, McCullough MP, Chappell JD, Denison MR, Stevens LJ, et al. An mRNA Vaccine against SARS-CoV-2 - preliminary Report. N Engl J Med. 2020. published online July 14. doi:10.1056/nejmoa2022483

9. Folegatti PM, Ewer KJ, Aley PK, et al. Safety and immunogenicity of the ChAdOx1 nCoV-19 vaccine against SARS-CoV-2: a preliminary report of a phase $1 / 2$, single-blind, randomised controlled trial. Lancet 2020;10249(396):467-478.

10. Zhu F-C, Guan X-H, Li Y-H, et al. Immunogenicity and safety of a recombinant adenovirus type-5-vectored COVID-19 vaccine in healthy adults aged 18 years or older: a randomised, double-blind, placebo-controlled, phase 2 trial. Lancet 2020;10249(396):479-488.
11. van Doremalen N, Lambe T, Spencer A, et al. ChAdOx1 nCoV-19 vaccination prevents SARS-CoV-2 pneumonia in rhesus macaques. bioRxiv Prepr Serv Biol. 2020. doi:10.1101/ 2020.05.13.093195.

12. Williamson EJ, Walker AJ, Bhaskaran K, Bacon S, Bates C, Morton CE, Curtis HJ, Mehrkar A, Evans D, Inglesby P, et al. Factors associated with COVID-19-related death using OpenSAFELY. Nature. 2020;584(7821):430-36. doi:10.1038/ s41586-020-2521-4.

13. Pawelec G, Weng NP. Can an effective sars-cov-2 vaccine be developed for the older population? Immun. Ageing. 2020;17. doi:10.1186/s12979-020-00180-2.

14. World Population Prospects - Population Division - United Nations. [accessed 2020 Aug 26]. https://population.un.org/ wpp/

15. Clark A, Jit M, Warren-Gash C, Guthrie B, Wang HHX, Mercer SW, Sanderson C, McKee M, Troeger C, Ong KL, et al. Global, regional, and national estimates of the population at increased risk of severe COVID-19 due to underlying health conditions in 2020: a modelling study. Lancet Glob Heal. 2020;8(8): e1003-17. doi:10.1016/S2214-109X(20)30264-3.

16. Davies M-A. HIV and risk of COVID-19 death: a population cohort study from the Western Cape Province, South Africa. medRxiv Prepr Serv Heal Sci. 2020;20145185. doi:10.1101/ 2020.07.02.20145185

17. Mbow M, Lell B, Jochems SP, Cisse B, Mboup S, Dewals BG, Jaye A, Dieye A, Yazdanbakhsh M. COVID-19 in Africa: dampening the storm? Science. 2020;369(6504):624-26. doi:10.1126/ science.abd3902.

18. Baqui P, Bica I, Marra V, Ercole A, van der Schaar M. Ethnic and regional variations in hospital mortality from COVID-19 in Brazil: a cross-sectional observational study. Lancet Glob Heal. 2020;8(8): e1018-26. doi:10.1016/S2214-109X(20)30285-0.

19. Roberton T, Carter ED, Chou VB, Stegmuller AR, Jackson BD, Tam Y, Sawadogo-Lewis T, Walker N. Early estimates of the indirect effects of the COVID-19 pandemic on maternal and child mortality in low-income and middle-income countries: a modelling study. Lancet Glob Heal. 2020;8(7):e901-8. doi:10.1016/S2214-109X(20)30229-1.

20. Kotlyar A, Grechukhina O, Chen A, et al. Vertical Transmission of COVID-19: asystematic review and meta-analysis. Am J Obstet Gynecol. 2020:S0002-9378(20)30823-1. published online July 31 . doi:10.1016/j.ajog.2020.07.049

21. Knight M, Bunch K, Vousden N, Morris E, Simpson N, Gale C, O'Brien $\mathrm{P}$, Quigley $\mathrm{M}$, Brocklehurst $\mathrm{P}$, Kurinczuk JJ, et al. Characteristics and outcomes of pregnant women admitted to hospital with confirmed SARS-CoV-2 infection in UK: national population based cohort study. BMJ. 2020;369:m2107. doi:10.1136/ bmj.m2107.

22. Ellington S, Strid P, Tong VT, et al. Morbidity and mortality weekly report characteristics of women of reproductive age with laboratory-confirmed SARS-CoV-2 infection by pregnancy status-United States. MMWR 2020;69(25):769-775. [accessed 2020 Aug 27]. https://www.cdc.gov/mmwr/mmwr_ continuingEducation.html ${ }^{\star}$ https://www.cdc.gov/coronavirus/ 2019-ncov/cases-updates/cases-in-us.html.

23. Holman N, Knighton P, Kar P, O’Keefe J, Curley M, Weaver A, Barron E, Bakhai C, Khunti K, Wareham NJ, et al. Risk factors for COVID-19-related mortality in people with type 1 and type 2 diabetes in England: a population-based cohort study. Lancet Diabetes Endocrinol. 2020;8(10):823-33. doi:10.1016/S22138587(20)30271-0.

24. PAHO PAHO. Epidemiological Alert: COVID-19 During Pregnancy - 13 August 2020 - PAHO/WHO | Pan American Health Organization. 2020; published online Aug 13. [accessed 2020 Aug 26]. https://www.paho.org/en/documents/epidemiologi cal-alert-covid-19-during-pregnancy-13-august-2020

25. Ratu FT, Ryan K, Gidi NW, Vereti I, Girma T, Oats J, Bucens I, Robinson A, von Mollendorf C, Russell FM, et al. Direct and indirect effects of COVID-19 on perinatal outcomes in low- and 
middle-income countries. Gates Open Res. 2020;4:108. doi:10.12688/gatesopenres.13156.1.

26. Heath PT, Le Doare K, Khalil A. Comment Inclusion of pregnant women in COVID-19 vaccine development. Lancet Infect Dis 2020;9(20):P1007-1008. doi:10.1016/S1473-3099(20)30638-1

27. Arvin AM, Fink K, Schmid MA, Cathcart A, Spreafico R, HavenarDaughton C, Lanzavecchia A, Corti D, Virgin HW. A perspective on potential antibody-dependent enhancement of SARS-CoV-2. Nature. 2020;584(7821):353. doi:10.1038/s41586-020-2538-8.

28. Moreira LP, Watanabe ASA, Camargo CN, Melchior TB, Granato C, Bellei N. Respiratory syncytial virus evaluation among asymptomatic and symptomatic subjects in a university hospital in Sao Paulo, Brazil, in the period of 2009-2013. Influenza Other Respi Viruses. 2018;12(3):326-30. doi:10.1111/ irv.12518.

29. Neal EFG, Flasche S, Nguyen CD, et al. Associations between ethnicity, social contact, and pneumococcal carriage three years post-PCV10 in Fiji. Vaccine 2020;38(2):202-11.

30. Public Health Agency of Sweden T. Covid-19 in schoolchildren A comparison between Finland and Sweden. [accessed 2020 Aug 26]. www.folkhalsomyndigheten.se/publicerat-material/.

31. Stein-Zamir C, Abramson N, Shoob H, Libal E, Bitan M, Cardash T, Cayam R, Miskin I. A large COVID-19 outbreak in a high school 10 days after schools' reopening, Israel, May 2020.
Eurosurveillance. 2020;25(29):2001352. doi:10.2807/1560-7917. ES.2020.25.29.2001352.

32. Szablewski CM, Chang KT, Brown MM, Chu VT, Yousaf AR, Anyalechi N, Aryee PA, Kirking HL, Lumsden M, Mayweather E, et al. SARS-CoV-2 Transmission and Infection Among Attendees of an Overnight Camp - georgia, June 2020. MMWR Morb Mortal Wkly Rep. 2020;69(31):1023-25. doi:10.15585/mmwr. mm6931e1.

33. Heald-Sargent $T$, Muller WJ, Zheng X, Rippe J, Patel AB, Kociolek LK. Age-related differences in nasopharyngeal severe acute respiratory syndrome coronavirus 2 (SARS-CoV-2) Levels in patients with mild to moderate coronavirus disease 2019 (COVID-19). JAMA Pediatrics. 2020;174(9):902. doi:10.1001/ jamapediatrics.2020.3651.

34. L'Huillier A, Torriani G, Pigny F, Kaiser L, Eckerle I. CultureCompetent SARS-CoV-2 in nasopharynx of symptomatic neonates, children, and adolescents. Emerg Infect Dis. 2020;26 (10):2494-97. doi:10.3201/eid2610.202403.

35. Viner RM, Bonell C, Drake L, Jourdan D, Davies N, Baltag V, Jerrim J, Proimos J, Darzi A. Reopening schools during the COVID-19 pandemic: governments must balance the uncertainty and risks of reopening schools against the clear harms associated with prolonged closure. Arch Dis Child Mon. 2020:archdischild2020-319963. doi:10.1136/archdischild-2020-319963. 


\section{University Library}

\section{- M M N E R VA A gateway to Melbourne's research publications}

Minerva Access is the Institutional Repository of The University of Melbourne

Author/s:

Russell, FM;Greenwood, B

Title:

Who should be prioritised for COVID-19 vaccination?

Date:

2020-10-30

Citation:

Russell, F. M. \& Greenwood, B. (2020). Who should be prioritised for COVID-19

vaccination?. HUMAN VACCINES \& IMMUNOTHERAPEUTICS, 17 (5), pp.1317-1321.

https://doi.org/10.1080/21645515.2020.1827882.

Persistent Link:

http://hdl.handle.net/11343/278149

License:

CC BY-NC-ND 